\title{
A study on Incidence of Viral Infections in Multitransfused Hemophilia Patients
}

\author{
Gira P. Mankad ${ }_{1}$, Sonal Joshi 2 Kiran Avashiya 2 , S.P.Singh 3 \\ M.V.M. Sci. \& HSc. College, Rajkot \\ Hemophilia Society, Rajkot Chapter. \\ Head, Department of Biosciences, Saurashtra University, Rajkot
}

\begin{abstract}
Hemophilia is an inherited bleeding disorder. In majority patients either clotting factor vii is in low level (Hemophilia A) or clotting factor ix is deficient (Hemophilia B). For the management of hemophilia, a patient needs to be transfused purified factor preparation or cryoprecipitated plasma. This makes patient susceptible to transfusion transmitted infections. In our study 115 patients were screened for HBsAg, HCV and $H I V$ antigen markers to check safety of cryoprecipitate they receive. Only one person was found to be HBsAg positive and one person was HCV positive. No seropositivity for HIV was found. Advance procedure for virus inactivation and strictly mainting a pool of selected donors for plasma can be major causes for such rate of viral infection in hemophilic patients.
\end{abstract}

Key Words: Hemophilia, Blood Transfusion, Transfusion Transmitted Viruses

\section{Introduction}

Hemophilia is a genetic disorder linked to $\mathrm{x}$ chromosome. Males suffering from this disorder mostly lack either clotting factor vii or ix. In rare cases there may be deficiency of other factors. As a result they loose substantial amount of blood due to injuries or spontaneous bleeding. They require to be treated with purified factors or fresh frozen plasma. With increase in age and activities there are chances of getting microbial infections due to multiple transfusions.

\section{Materials and methods}

At Hemophilia Society, Rajkot a group of 156 hemophilic patients were registered initially in the study, at the end of the study in 2008 we have registered 232 hemophilic patients. Transfusion and clinical records of all patients were maintained throughout the study.

\section{Serological study}

Frozen samples were tested after the study period for various viral markers in the same laboratory by one person using the same batches of reagents and kits. Tests were carried out by commercially available, third generation, enzyme linked immunosorbent assay (ELISA) for the following TTD markers: (i) HBsAg (Microscreen HbsAg ELISA Test Kit by Span Diagnostics) (ii) antibodies to HCV (SP- NANBASE C-96 3.0 test kit by General Biological Corp.); (iv) anti HIV I/II (Enzaids HIV 1+2 ELISA test kit by Span Diagnostics). Tests could not be repeated due to lack of serum samples and in some cases because of high reagent cost.

\section{Results}

Hemophilia a hereditary disorder of Coagulation results in deficiency of Factor VIII (Hemophilia A) or Factor IX (Hemophilia B) or rarely due to deficiency of other clotting factors.

Table 1

Comparison of Factor Deficiency among Hemophilic Patients.

\begin{tabular}{|c|c|c|c|}
\hline Sr.No. & Factor & NO. & $\%$ \\
\hline 1 & VIII & 193 & $83 \%$ \\
\hline 2 & IX & 32 & $14 \%$ \\
\hline 3 & Others & 07 & $3 \%$ \\
\hline
\end{tabular}

Table explains Factor VIII deficiency was observed in $83 \%$ of patients while $14 \%$ patients were having deficiency of factor IX and 3\% of patients were having deficiency of other factors such as factor V. Factor VIII deficiency is most commonly found among Hemophiliacs followed by deficiency of Factor IX and other factors. 


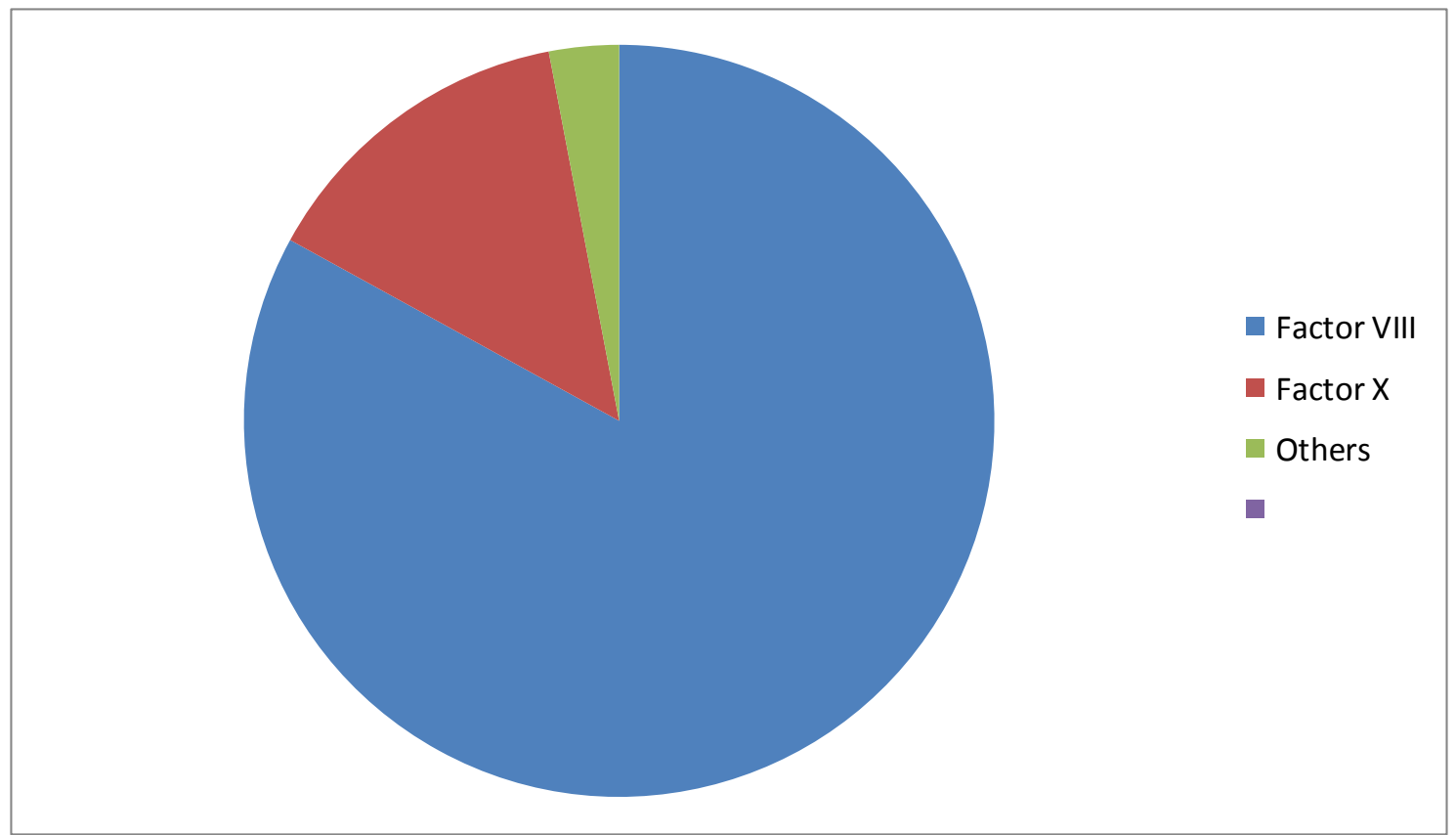

Hemophilia is a chronic physical condition affecting the child from birth. Age group wise distribution was studied.

Table 2

Age wise distribution of Hemophilic Patients

\begin{tabular}{|c|c|c|c|}
\hline Sr.no. & Age group & No. & $\%$ \\
\hline 1 & $0-5$ year & 17 & 08 \\
\hline 2 & $6-15$ year & 75 & 32 \\
\hline 3 & $16-30$ year & 103 & 44 \\
\hline 4 & 31 year & 37 & 16 \\
\hline
\end{tabular}

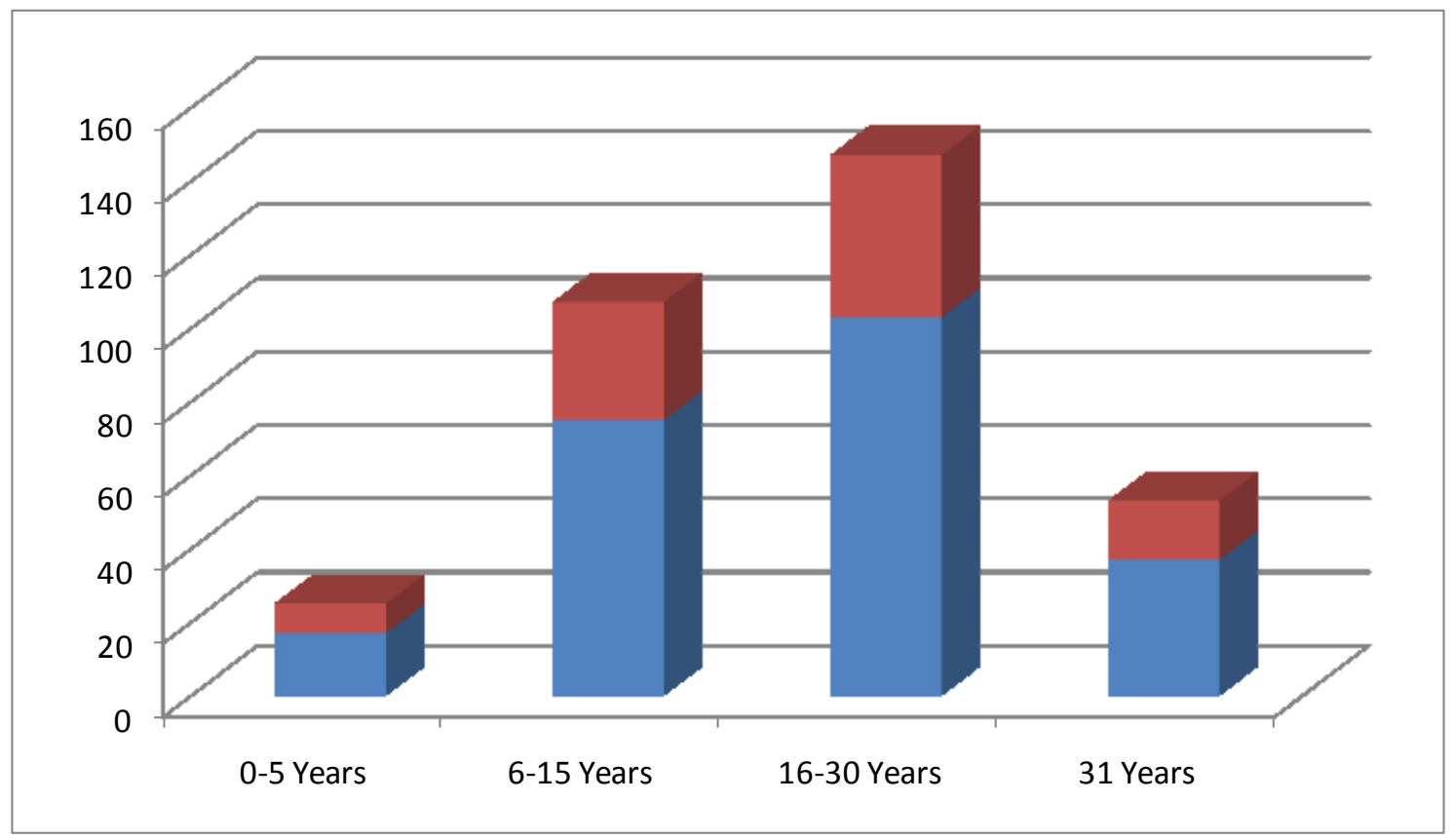


Figure indicates majority of the hemophilia patients under present study belonged to age group between 16 and 30 followed by 6-15 years, above 31 years of age and least number of patients were in 0-5 year age group. This data suggests good prenatal counseling and efficient management of the disease in patients.

Hemophilia can be mild, moderate, or severe, depending on how much clotting factor is in the blood. We carried out factor estimation in order to establish severity of the disease.

Table 3

Distribution of Hemophilic Patients according to Factor Level

\begin{tabular}{|c|c|c|c|}
\hline Sr. No. & Factor Level & No. & $\%$ \\
\hline 1 & $<1$ & 95 & $40.94 \%$ \\
\hline 2 & $1-5$ & 85 & $36.64 \%$ \\
\hline 3 & $>5$ & 52 & $22.42 \%$ \\
\hline
\end{tabular}

Figure shows Factor level in most hemophilia patients was found to be either below 1(40.94\%) or between 1 and $5(36.64 \%)$. There were $52(22.42 \%)$ patients with factor level of more than 5. Majority of the patients under our study have severe hemophilia.

Distribution of Hemophilia patients according to Factor Level
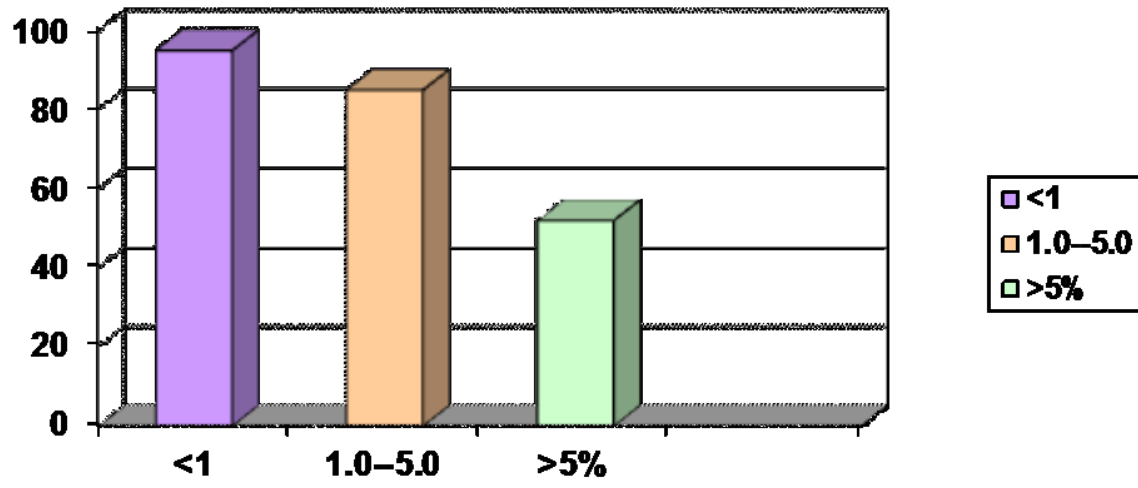

Prevalence of Viral infections among Hemophilic Patients

Table 3

\begin{tabular}{|c|c|c|c|}
\hline Sr.no. & Positivity & No. & $\%$ \\
\hline 1 & HBS Positive & 1 & $0.43 \%$ \\
\hline 2 & HCV Positive & 1 & $0.43 \%$ \\
\hline 3 & HIV Positive & 00 & $00 \%$ \\
\hline
\end{tabular}

Figure shows that out of 232 patients, only 1 patient was found to be HBsAg positive and 1 was HCV positive. All patients were HIV negative.

Because of the advanced procedures of inactivation of viruses such infections are less likely to occur.

\section{Discussion}

Blood transfusion currently faces interesting challenges. While advances have been dramatic, both in terms of technology and organizational up gradation in developed countries, blood transfusion in developing countries still tend to stagnate with acute shortages, lack of component therapy and safety problems.

HBsAg Seropositivity in Hemophilic patients

\begin{tabular}{|c|c|c|c|c|c|}
\hline No. & Author & Year & Place & No. Tested & Positivity $\%$ \\
\hline 1 & Nebbia G. & 1986 & Milan, Italy & 54 \\
\hline 2 & Sengupta B. & 1992 & Calcutta & 37 \\
\hline 3 & Chow M.P. & 1991 & Taiwan & 11 & $24.3 \%$ \\
\hline 4 & Ghosh K. & 2000 & ICMR, Mumbai & 400 & $9 \%$ \\
\hline
\end{tabular}




\begin{tabular}{|c|c|c|c|c|c|}
\hline 5 & Sharifi-mood B. & 2007 & Iran & 81 & $4.9 \%$ \\
\hline 6 & Present Study & 2010 & Rajkot, India & 232 & $0.43 \%$ \\
\hline
\end{tabular}

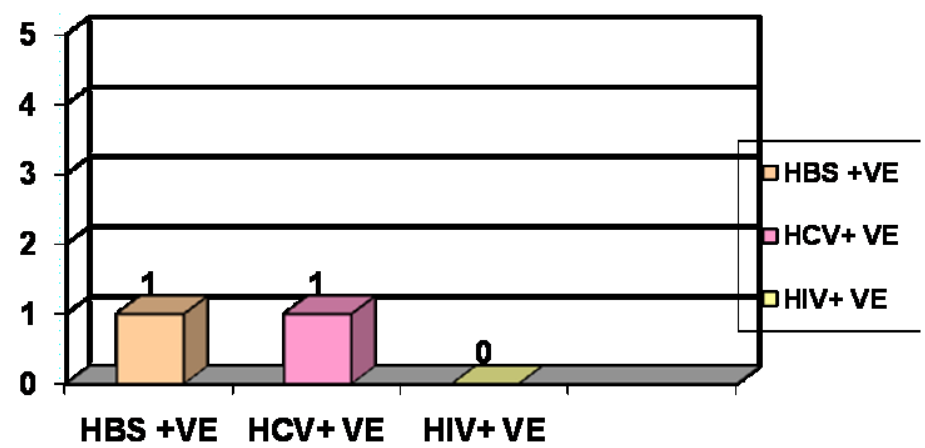

As showr

ie percentage positivity Jhilia Society receives Fresh Frozen Plasma from a selected pool of donors carefully screened and restricted only for this purpose. This explains low seropositivity of Hepatitis B marker in our study. The reason for low seropositivity can be attributed to vaccination against Hepatitis B to all Hemophiliac subjects.

Prevalence of HCV among Hemophiliacs depends primarily upon the amount and type of product transfused. Almost universal exposure to $\mathrm{HCV}$ is observed in Hemophiliacs receiving untreated commercial clotting factor concentrates. However, Hemophiliacs receiving appropriately inactivated coagulation components from single donor cryoprecipitate generally remain Anti-HCV negative (Brettler, 1990).

$\underline{\text { HCV Seropositivity in Hemophilic patients }}$

\begin{tabular}{|c|c|c|c|c|c|}
\hline No. & Author & Year & Place & No. Tested & Positivity \% \\
\hline 1 & Chow M.P. & 1991 & Taiwan & 11 & $100 \%$ \\
\hline 2 & Ghany M.G. & 1996 & Louisiana, USA & 100 & $79 \%$ \\
\hline 3 & Samimi-Rad K. & 2007 & Tehran, Iran & 76 & $43.4 \%$ \\
\hline 4 & Sharifi-mood B. & 2007 & Iran & 81 & $29.6 \%$ \\
\hline 5 & Sengupta B. & 1992 & Calcutta & 37 & $27 \%$ \\
\hline 6 & Ghosh K. & 2000 & ICMR, Mumbai & 400 & $23.9 \%$ \\
\hline 7 & Present Study & 2010 & Rajkot, India & 232 & $0.43 \%$ \\
\hline
\end{tabular}

HCV seropositivity in hemophilic patients found to be varying from $100 \%$ to $0.43 \%$ in various studies. As explained earlier policy of giving single donor cryoprecipitate to hemophiliacs is the reason of low seropositivity in our study.

Because of the enormous risk involved in transmission of HIV through blood, safety of blood and blood product is of paramount importance. Currently, the risk of transmission of HIV through transfusion is minimal, because effective preventive strategies, including new laboratory tests, have been implemented.

\section{HIV Seropositivity in Hemophilic patients}

\begin{tabular}{|l|l|l|l|l|l|}
\hline No. & Author & Year & Place & No. Tested & Positivity $\%$ \\
\hline 1 & Chow M.P. & 1991 & Taiwan & 11 & $82 \%$ \\
\hline 2 & Sultan Y. & 1987 & Paris, France & 2049 & $48 \%$ \\
\hline 3 & Ghany M.G. & 1996 & Louisiana, USA & 100 & $42 \%$ \\
\hline 4 & Sengupta B. & 1992 & Calcutta & 37 & $24.3 \%$ \\
\hline 5 & Ghosh K. & 2000 & ICMR, Mumbai & 400 & $3.8 \%$ \\
\hline 6 & Present Study & 2010 & Rajkot, India & 232 & $00.00 \%$ \\
\hline
\end{tabular}

The virus that causes AIDS (HIV) can be carried in clotting factors as well as plasma. However, there has been no documented case of these viruses being transmitted during replacement therapy in our present study. Transmission of viruses has been prevented by careful screening of blood donors, testing of donated blood products, treating donated blood products with a detergent and heat to destroy viruses. 


\section{References}

[1]. Chow MP, Lin CK, Lin JS, Chau WK, Ho CH, Chen SY, Lee SH, Yung CH. HIV, HBV and HCV seropositivity in hemophiliacs.Zhonghua Min Guo Wei Sheng Wu Ji Mian Yi Xue Za Zhi. 1991 Nov; 24(4):339-344.

[2]. Ghany MG, Leissinger C, Lagier R, Sanchez-Pescador R, Lok AS. Effect of human immunodeficiency virus infection on hepatitis C virus infection in hemophiliacs.Dig Dis Sci. 1996 Jun; 41(6):1265-1272.

[3]. Ghosh K, Joshi SH, Shetty S, Pawar A, Chipkar S, Pujari V, Madkaikar M, Pathare AV, Jijina F, Mohanty D.Transfusion transmitted diseases in haemophilics from western India. Indian J Med Res. 2000 Aug; 112:61-64

[4]. Nebbia G, Moroni GA, Simoni L, Belli M, Carnelli V.Hepatitis B virus infection in multitransfused haemophiliacs.Arch Dis Child. 1986 Jun; 61(6):580-584

[5]. Samimi-Rad K, Shahbaz B.Hepatitis C virus genotypes among patients with thalassemia and inherited bleeding disorders in Markazi province, Iran.Haemophilia. 2007 Mar; 13(2):156-163. Review.

[6]. Sengupta B, De M, Lahiri P, Bhattacharya DK Sero-surveillance of transmissible hepatitis B \& C viruses in asymptomatic HIV infection in haemophilics.Indian J Med Res. 1992 Nov;95:256-8.

[7]. Sharifi-Mood B, Eshghi P, Sanei-Moghaddam E, Hashemi M.Hepatitis B and C virus infections in patients with hemophilia in Zahedan, southeast Iran.Saudi Med J. 2007 Oct; 28(10):1516-1519.

[8]. Sultan Y.Epidemiology of HIV infection in multitransfused hemophilic patients in France. French Study Group in Hemophilia.Nouv Rev Fr Hematol. 1987; 29(4):211-214. Erratum in: Nouv Rev Fr Hematol 1987; 29(6):436. 